\title{
Differential Geometry, the Informational Surface and Oceanic Art: The Role of Pattern in Knowledge Economies
}

\author{
Susanne Küchler (UCL)
}

\begin{abstract}
:
Graphic pattern (e.g. geometric design) and number based code (e.g. digital sequencing) can store and transmit complex information more efficiently than referential modes of representation. The analysis of the two genres and their relation to one another has not advanced significantly beyond a general classification based on motion centred geometries of symmetry. This paper examines an intriguing example of patchwork coverlets from the maritime societies of Oceania where information referencing a complex genealogical system is lodged in geometric designs. The key to the role of pattern in logging and transmitting genealogical knowledge is the operation of an algebraic system called a noncommutative group described by the anthropologist Claude Levi-Strauss as the 'canonical formula'. Like in a Rubik Cube, where patterns behave in an immanent, rotational and transformative manner, quilted patterns, here argued to prototype the behaviour of the socio-political system, expose in the assembled pieces of patchwork a heterogeneity of locally discrete and yet globally continuous spaces, the understanding of which legitimizes rights to land and to power. This understanding, comparable to the guiding principles of differential geometry, is central to the workings of maritime navigation and Oceanic genealogical systems alike. Rather than being decipherable through vision alone, the prototypicality of pattern is founded on the knowledge of an algebraic system that is deployed in its assemblage. By drawing attention to the interplay of graphic pattern and number based code and its role in the knowledge economies of maritime societies, the paper offers new insight into possible ways of designing a digital informational surface that captures as quality the behaviour of an operational system, allowing both for differentiation and integration. Researchers interested in the way graphic shapes carry an idea of relation will take from this example the impetus to rethink how to model societal integration without falling back onto epistemic paradigms that deny the value of multiplicity and heterogeneity.
\end{abstract}

Keywords: Differential Geometry; Algebraic Systems; Maritime Navigation; Pattern Analysis; Informational Surfaces.

To anyone accustomed to a landscape of lines ${ }^{1}$, the sea may appear flat and lacking in distinctive views that could aid navigation. The study of the navigation practices of Micronesian Islanders has shown, however, that seascape carries information in the form of an interplay of visible and invisible elements (Gladwin, 1970; Gell, 1985). The calculated relation between wind, current and underwater elevations is indexed by the crests of waves whose shape is sensed as they hit the canoe one by one in a sequence modelled in distinctly patterned yet otherwise non-representational artefacts. Three different types of so called stick charts exist: an abstract chart prototyping the behaviour of the system, used for instruction; and two charts mapping actual locations, actual islands and specific landing sites (Ascher, 2002: 89-125). Rather than voyaging being a process aided by mapping the movement of the canoe between islands in relation to independent and pre-existing variables, the Micronesian voyager thus maps the canoe's journey by assigning spatial and 
metric values to this temporal process, thus rendering the canoe itself stationary, with iterative and repetitive patterns of surface swells moving past until a certain sequence and articulation of waves finally enable the recognition of the anticipated island (Hutchins, 1995: 118). The stick charts are in effect mapping the journey as an assemblage of differentiated, three-dimensional neighbouring spaces, whose sequence and magnitude is captured both as prototype and as record of the experience of relations underpinning the complex systemic interplay of currents, winds and elevations. As prototypes stick charts are at once metric and geometric, modelling relations and their systemic behaviour across visible and invisible domains. They are in fact exemplifying the enigma of seemingly representational surfaces that reference relations whose immanent relational constitution makes them virtually impossible to unravel and which nevertheless inform understanding of complex systemic relations across analogous domains. ${ }^{2}$

We might disregard the epistemic work such prototypes do as culturally specific and limited to maritime navigation and yet by doing so we would miss out on understanding how stick charts can be engaged with knowingly and what difference the way they are engaged with makes in culture and society. For as instruments of instruction and recollection, Micronesian stick charts draw out ideas that transcend the specific context of their use and cultivate an aesthetic that canonizes informational content in a way that is, as we will see, of peculiar relevance to the operation of knowledge economies within wider Oceania. The ubiquity, translatability and continuity of the ideas that inform the capture of seascape as a system of sequences and relations which make strategic navigation possible is evidenced by a artefacts produced across island Polynesia whose central role in rituals sustaining social polities of great complexity spanning many generations is well known (Brunt et.al. 2011). There is the late eighteenth-century figure-shaped casket from the island of Rurutu that is famous for its surface budding with iterated and replicated miniature extensions of itself; and the only remaining artefact from the pre-Christian era in the Cook Islands, covered along the length of 7 metre shaft with iterated and self-similar figures. Both artefacts were central to the practice of secondary burial and key to establishing an artificial sociability that encompassed both the living and the dead (Babadzan (1993; 2003). The ritual, which the Cook Islands in Eastern Polynesia shared with Tahiti and Hawaii, had three stages, each being defined in relation to the manipulation of this mummy-like object: the unwrapping of the object, effecting the death or departure of the dead; the exchange of feathers and of cloth as the distributing of the remains of the dead; the re-assemblage or 'renewal' of the object, invoking the return and emplacement of the dead and the period of abundance. This ritual established a contractual relation with the multitude of the dead, while also giving visual expression to genealogical relatedness in iterative, transitively replicated and fractal images. When these rituals ceased to be practised with the conversion to Christianity, women in 
these islands took over the task of managing the mapping and managing a complex system of genealogy supporting some of the most hierarchical social systems in the world. From Hawaii to Tahiti and the Cook Islands in a region known as Eastern Polynesia, the artefacts that sustain the knowledge of the genealogical system today take the form of assemblages of pieces of cloth into precisely measured coverlets known as tivaivai (tifaifai) (Arkana 1986; Jones 1973; Hammond 1986; Küchler and Eimke 2009). [figure 1]. Exchanged as gifts in events that punctuate the life cycle of persons and social groups, the knowledge of the metric, underpinning the assemblages and acting as vehicle for the ideas pertaining to the navigation of genealogical relations, extend beyond the islands to the furthest reaches of transnational communities. Patchwork today effectively blends the heterogeneity of the local with the global, creating social polities that differentiate themselves in terms of the scale of their reach and the heterogeneity of their composition.

This paper will argue that the enigma of a prototype which references relations both external and internal to itself raises a question that reaches far beyond the confines of particular maritime societies in which it serves to model the behaviour of complex social, political and even ecological systems, as the anthropologist's Frederick Damon's (2016) recent reanalysis of the construction of canoes in the Massim region of island Melanesia in relation to environmental knowledge has shown. From stick-charts to figurative assemblages to patchwork and to canoes, the protypical artefacts of Oceania have in common to model the behaviour of complex systems by interpolating shape and sequence in ways that defy our expectation of a distinction of graphic (e.g. geometric designs) versus metric coding (e.g. digital sequencing). The question in the words of the historian of mathematics Albert Lautman (2011) is what the relation between 'mathematics, ideas and the physical real' is that might allow such artefacts to perform as vehicles of epistemology.

The question of the mathematics and the ideas that inform the diverse artefacts of Oceania can, I will argue in this paper, not be dissociated from the experience of the maritime environment which requires information to be moved across distances to be engaged with as knowledge via forms that reflect the highly artificial sociality such transmission creates as well as the technical command over complex relations between visible and invisible forces of which the sequence and shapes of waves at the surface of the ocean are an observable qualisign (c.f. Simmel 1950). In fact, the stick chart and its analogous prototype, the patchwork, throw up ideas of space-time we can recognize as those of differential geometry, drawing out the idea of space not as an exterior, measured and thus finite entity, but as existing between points, each of differential value. ${ }^{3}$ It is not insignificant to my discussion of the enigma of the geo-metric prototype that the ideas underpinning differential geometry have informed the interest in cinematography uniting the work of Henri Bergson and Gilles Deleuze, both having been acutely familiar with the science 
of the nineteenth century mathematician Bernhard Riemann (1826-1866) who first described the approach to curved three dimensional space departing in his treatment of space as mathematical object from the existing Euclidean approach that had investigated the straight line and the plane (Duffy 2013: 89-117). Riemann had conceived of a surface as a topological space composed of points that form neighbourhoods which themselves map onto a complex plane consisting of potentially infinitely many 'sheets' that have many complicated structures and interconnections (Duffy 2013: 108). Deleuze's (1993/1988) early work on the 'fold' draws on Riemann's work to capture the relation between mathematics and ideas that underpinned the formalized aesthetic known as the Baroque and it is this work that has inspired the analysis of Oceanic prototypes extended here, rather than his better known work on the manifold and self-organizing branching interconnections, captured as the 'rhizome' in his work on A Thousand Plateaus (Deleuze and Guattari 1987/1980).

With Riemannian differential geometry in mind we can return with fresh eyes to the formalized aesthetic made manifest on surfaces used for instruction and recollection and engaged with knowledgeably and ask how it is that they sustain social systems of great complexity and resilience (Starr 2013). ${ }^{4}$ This paper will take as its case study the piecework coverlet made in the Cook Islands. Its archipelago of fifteen small islands scattered over 2 million square kilometres, stretching between Tonga and Samoa and French Polynesia is inhabited by Maori speaking peoples who are known to practice the most complex genealogical system, differentiating not just between elder and younger brother who compete over access to partially genealogically ordained and partially achieved power, but also between autochthonous and foreign forms associated with access to power over people and power over land. A person's life project is informed by genealogically qualified relations that are expressed quantitatively in the measure applied to three distinct and yet interconnected modalities of assemblage, all made to be gifted at major life ceremonies and stored in trunks until they are rendered permanently invisible by being wrapped around the dead in the grave. The coverlets are assembled from precisely measured and counted composite parts that are repeated over the surface of the cloth in a symmetrical, iteratively replicated and transitively arranged pattern, ostensibly featuring flowers whose striking verisimilitude can equally be represented by abstract patterns composed of coloured pieces cut into geometric shapes such as diamonds, hexagons or octagons. This paper will concern itself with the question of the 'workings' of such an assembled surface whose aesthetics is key to an understanding of relations that are as complex as they are vital to everyday decision making and life defining strategies (Siikala 1991).

Sociability in the Cook Islands is as 'stylized' (c.f Simmel 1950) as its coverlets, with the assemblages visible as patterns on the surfaces of patchwork being fanned as gifts throughout a woman's life cycle, cloaking near and distant relations into economically 
effective polities. Everything that moves, from money through to building materials for houses, travels along the path taken by coverlets that are sent out by households into the furthest reaches of the many transnational communities where Cook Islanders have set up home away from islands. The polity rarely comes together physically in one place, but for two occasions that mark the role of patchwork as modelling ideas vital to an economy driven by the knowledge of how to achieve such an assemblage: the first such occasion is the first haircutting of the first born son of a woman heading up a household whose coming of age is marked with a ceremonial cutting of his hair, sat upon a stitched patchwork and listening to the narration of his place in the genealogy that defines the relations of which he will be a part; the second such occasion is the burial of the head of the household or a close relation who is buried, wrapped in the patchwork returned by the extended polity to be lowered into the tomb like structure that sits, in the shape of a minute house, next to the house once occupied by the deceased. The polities in short are image based, yet these images are not merely metaphorically referencing an emblematic allegiance, but are themselves the gateway to accessing the knowledge that ensures effective membership. As the early twentieth century German sociologist Georg Simmel (2005)stated so brilliantly in his essay on Rembrandt, when sociability is artificial the art of social forms is equal to the social forms of art.' ${ }^{5}$ Important here is Simmel's argument in his essay against a perception dominated approach, in that he foregrounds not the seen, but rather the role of imagination in deduction. ${ }^{6}$ What is the relation we may ask with Simmel in mind between the patterned assemblage of pieces on the surface of the patchwork and the genealogical imagination so that the patchwork offers access to knowledge vital to claiming land and rights associated with the complex management of the distributed polities of the Cook Islands? For as the young man sits on the patchwork and as the layers of patchwork are cloaking the body in the grave, an idea of society is given form to that that is as plastic as it is graspable only in the abstract.

Patchwork indeed gives form to an understanding of the nature of a biographical relation and how to extend it beyond the person. It does this not just with reference to its own composition, but to its formal relation to other patchwork, with every patchwork articulating a specific modality of relation in its construction [Figure 2]. As in the instruments that guide the navigation between islands, there are three technical modes of assemblage for three different types of biographical relation: Work colleagues and friends as well as all short term connections associated with sharing the experience of a specific place are gifted a coverlet made as a cut out - a so called 'manu' or 'bird' design - made by folding a large piece of cloth 4 times and cutting a design into the thus folded material so that, when unfolded, the pattern is replicated four fold across the surface in such a manner that foreground and background are oscillating to the eye; relatives by marriage, especially relations defined with 
reference to the marriage of brother and sister, are gifted coverlets made as applique design - a so called ta taura or cut and linked design - whereby the cut out shapes are repeated and arranged symmetrically in a circular motion across the surface of the coverlet; and finally, a grandmother gift a taorei or piecework design to her adopted granddaughter who as 'foreigner' repeats the path taken by an apical ancestor whose arrival on the island is recalled to legitimize power over land. Taorei are the most complex coverlet, produced only in the Cook Islands famous for its complex genealogical system (Siikala 2006). The taorei piecework is composed of identical, iteratively replicated and transitively arranged core patterns $(p u)$, made of precisely measured, identically cut pieces in work that is divided between four to eight women, each stitching a triangular part of the core pattern known and recalled as a sequence of numbers and colours. In ways that is to be unravelled in the course of this paper, it is the number sequence that serves as key to allowing the assemblage of pieces at the surface of the patchwork to instruct and remind of the precise positioning of persons and their polities in the complex system of genealogy and its resulting polities.

It is to this latter piece-work coverlet in the main that I will direct attention in this paper. In doing so, I will expose the algebraic logic and the geometric imagination it gives rise to at work in the construction of what may seem a flat, merely decorative surface and show how it is that the workings of the genealogical system can be deduced from a seemingly abstract surface pattern (Küchler and Were 2005). Patchwork is a vehicle for navigating biographical relations and plot life projects with as much surety as the navigation of the ocean and it is its formalized aesthetic surfacing as pattern that serves to instruct, remind and inform, turning a mere artefact into an epistemic tooling. Before returning to unravelling how patchwork is able to do its epistemic work, it is necessary to digress just a little to the ideas surrounding personhood and most importantly time that the patchwork has to meet - ideas that are well known for their ubiquitous and lasting nature across the island societies of Oceania (c.f. Henari et. al. 2007).

\section{Information, immanence and closure}

The attention to surface not just as mediating interface for complex systems, but as modelling in its composition the behaviour of the system of which it is itself a part is no longer exotic, as the philosophy and engineering of robotics and computer interaction proceed to give shape to material processes that are interlacing thought, action and world in a duality of action and action representation (Gallese 2000; Clark 2001; Wiberg and Robles 2010). This contemporary fascination with surface as 'meshwork' ${ }^{7}$ of mind and action opens up an opportunity for us to revisit the question of how surfaces work and the difference they make to society and culture, and much thinking has been devoted to this already in anthropology. 
From explorations of how we think through and with things to explanations of how ways of knowing and doing are inscribed into even the most mundane of objects, there is no shortage of theorists concerned with the question of how mind and material world cohere (Knappett, 2005; Henari et. al., 2007; Malafouris, 2013). Although brilliant and persuasive, the problem with these theories is that they propose artefacts to work as vehicles for the human propensity to extend its mind into the world, rather than exposing, via ethnography, the subtle interrelation between mind making and world making in ways that accounts for the difference made by 'mindware' to culture and society.

There is no doubt that artefacts function as surfaces that, on account of their referential qualities, play a vital role in assisting distributed cognition and the extending of persons beyond the physical and temporal confines of biographically imagined relations (Gell 1998). The problem occurs when we broaden this argument to societies, such as the Polynesian Maori, where information (energy/light) is conceived as pervasive and where not its distribution, but its arrest, in the sense of achieving immanence in bodies, places and things, is a matter of concern, thought to safeguard well-being, fecundity and prosperity alike. How to achieve immanence is subject to a number of actions upon bodies and body like entities, from rivers to land to anything that grows or emerges from it. Artefacts that punctuate transitions in the life cycle, such as birth and death, serve to achieve closure analogically by standing in for persons whose internally held relations are temporally exposed and in danger of dissipating.

The idea of closure as key to connectivity and of relational immanence is not easily reconciled with an interpretative framework that assumes linear point configurations (networks) and the emblematic expression of relations to govern the making of informational surfaces. As surfaces that are guided by an idea of closure tend to be made of fabric and fabric like materials that are malleable, neighbourhood creating and iterative in their relation to one another as they serve to cloak and contain, artefacts that serve such closure tend to be classified as 'textile'. I am not so much concerned here with underscoring the gendered implications of this classification as with the oversight that follows such classification placing seemingly two dimensional artefacts in opposition to three dimensional sculpture -, but with the underpinning geometric assumption grounded in Euclidean geometry that has hindered a productive approach to such flat surfaces and their informational capacity. Surfaces that on account of their flat and surface patterned form cordon, sift or funnel what is inside or outside, behind and in front, and assign spatial values to temporal sequences, offering up to future actions ideas that have never been thought and habits that never were, are still lost to theory, awaiting recovery via an approach that uncovers the mathematical and geometric thinking that dwells in seemingly innocuous folds, requiring an imagination that is able to translate two dimensional into three dimensional form and back again. 
Anthropology is well versed in studying artefacts whose surfaces exude patterns that lack apparent representational capacity and yet permit an ordering to be deduced whose systemic logic is of interest to both the ethnographic and the Kantian project of illustrating qualities of the psychic unity of humankind or deep structures of the Human Mind have enchanted many (Levi-Strauss 1966; Forge 1973; Washburn and Crowe 1988; 2004). More recently the advent of chaos theory in anthropology (Mosko and Damon 2005; Mosko 2005: 17) has led to a return to a concern with questions directed to the nature of the logic at work in abstract patterning, drawing on articulations of fractals, self-similarity and holography in graphic systems that drawn, danced, plaited or beaten into surfaces, both on and off the body. This approach sets out to give recognition to the non-linearity and self-organization at work in complex social systems, drawing for inspiration on the classical work of the anthropologist Edmund Leach (1960) that had shown non-linear topological systems to serve as model of political relations in Highland Burma and on the work of Louis Dumont (1980) whose theory of hierarchy shows the relation between purity and impurity in India to follow a series of recursive and reversible inclusions rather than a linear series of inequalities (c.f. Kapferer 2010). My problem with the Chaos theory and its implicit approach to model social systems based on their affinity with self organizing natural systems is its divergence from classical work inspired by the structuralism of Claude Levi Strauss (1963) and the early twentieth century American anthropologist Franz Boas $(1911,1927)$ who had been concerned with the question of how such systems are engaged with knowledgeably. In relation to the material discussed in this paper, the question of how abstract pattern is intentionally applied so as to achieve closure and yet retain systemic capacity that bind the one into the many reasserts itself with a force that only the recent work of Patrice Maniglier (2006) attempts to give justice to. There is no space here to elaborate on the recovery of the work of Claude Levi-Strauss for a philosophical anthropology and it will have to suffice to point to his work as justification for the return to Levi-Strauss (1963 and 1969) much ignored insight into what he so aptly called the 'canonical formula' whose manifestations resonate across sensorial registers and are as mobile as they are intuitively recognized and engaged with imaginatively, cognisant of their inter-subjective validity.

For Levi-Strauss had understood the role of mathematics in deducing the understanding of relation which is delivered in its potency only by pattern and used this insight to create the rigorous method directed to studying seemingly random data on which anthropology relies till today. Seemingly unremarkable surfaces, visible as graphic designs drawn into the sand, twisted into string, plaited into palm fronds or woven into vines were first understood by the early anthropologist Abel Deacon (1934) who came to be stationed, at the start of the First World War, as missionary on the island of Ambrym in the archipelago of Vanuatu, south-west of mainland New Guinea in island Oceania. Trained in natural sciences 
in Cambridge, and thus acquainted with mathematics and physics Deacon was able to translate the geometric diagrams that were drawn, plaited and lashed by the islanders into an algebraic system called in mathematics a noncommutative group, which emphasizes relations between objects and rules of combination that allow for a coherent formal interpretation and prediction of transformations. The realization that patterns can be 'read' as a system of elements (such as real numbers) together with a system of abstract rules for their combination so that two sides of a formula can be transformed in relation to one another proved revolutionary in anthropology, its logic used by Levi-Strauss to decode the data left by Deacon further, revealing the existence of the most complex marriage system known to us, consisting of six classes (Levi-Strauss, 1969). It was the discovery of what Levi-Strauss termed the 'canonical formula,' consisting of the operational quality of so called quaternion groups, that enabled him to create the basis for the rigorous study of the quality or behaviour of kinship systems based on observable and quantified relations (Levi-Strauss 1963; Morava 2003; 2005:60; Gell 1998: 56).

It is not that Levi-Strauss's insight into the role of the 'canonical formula' in allowing the translation of three dimensional into two dimensional imagination had been totally lost to anthropology, but its mathematical properties enabling systems of transformation and identification that are both knowable and manipulatable had somehow vanished from view. Anthropologists thus made reference to graphic surfaces as capable of modelling complex social and biographical relations, offering a de-centred analytical vantage point that allows for the conception of social 'wholes' by those that all too often are deemed to require the anthropologist to reconstruct how a society works (Rio (2007). Others such as Frederick Damon (2016) have shown that seemingly non-graphic artefacts such as canoes encode the logic of the interplay of complex ecological and social system and permit a qualitative understanding of the strategic circulation of resource use across the diverse island ecologies based on the systematic study of the wood used in the construction of canoes. Much of this work is in part inspired by earlier work on body counting in Papua New Guinea by Jadran Mimika (1988) and Aletta Biersack (1982) that had shown number systems to convey the logic underpinning complex cosmological systems, arguing, by leaning on Levi-Strauss, that systems of body counting illustrate an alternative logic of calculative thought that exists in parallel to Western science where numbers are manipulated in the abstract, independent of pattern (c.f. Levi-Strauss 1966).

Meanwhile, however, the analysis of abstract pattern itself followed a different route altogether. While not removing its analysis not entirely from mathematics (Ascher 2002), the idea that abstract pattern is an index of an idea of relation that finds its expression in mathematical imagination was largely lost to anthropology as studies of pattern systems took their lead from the now classical work on pattern analysis by Dorothy Washburn and David 
Crowe $(1988 ; 2004)$. By proposing a study of pattern classification in terms of the properties of symmetry, Washburn and Crowe encouraged an approach that traces gestures, so called symmetry motions, that are active in the production of pattern, governed by motion centric geometries that repeat a single pattern or parts of a pattern in regular ways, with the motion maintaining the distance between the parts of a pattern. These symmetry producing motions are: translation, a shift by a given distance along a line), rotation about a point in a plane, mirror reflection across a line in a plane, and glide reflection (translation followed by mirror reflection. No relation is established with algebraic elements and rules for their combination that permit rotations of imagined geometric figures in three dimensional space even in the work of the late Alfred Gell (1998: 164), whose analysis of Marquesan art recognizes the 'psychological saliency of style' and the importance of the geometric logic that permits the translation of a three dimensional into a two dimensional image. ${ }^{8}$ Missed is a solution to the question of how such a translation, correctly identified by Gell as informational gesture,' could be executed intentionally and engaged with knowledgeably, enabling pattern to inform via deduction in more than a generic manner. Even the work of the American ethnomathematician Maria Ascher (2002), whose insight, that the very idea of relation is an inherently mathematical one, allowed her to expose the mathematics at work in diverse graphic systems, misses the chance to expose the systemic relation between algebraic and geometric imagination and the difference that the understanding of such a relation may make to how complex systems are imagined to behave and are engaged with forethought and strategic intent.

Support in suggesting that the idea of informational gesture alone may not suffice comes from a surprising corner, the work of the philosopher Michel Serres. In his work entitled Atlas (1994), Serres reflects on the emerging culture of information in which local and global phenomena are mapped by sequential, reversible and entropic flows that are made accessible to understanding via surfaces that reference the relational nature of topologically apprehended actions (cf. Connor, 2004). Serres's denunciation of linear thought, preoccupied with tracking the movement of solid objects such as bodies in space, allows him to challenge our conventional understanding of surface as flat and metric form, instead presenting it as 'folded' time, a way of mapping time by giving it a spatial value by marking the infinitesimal neighbourhood of each point. Serres uses the idea of fabric to allude to the sequential relations between such neighbourhoods that compose the seemingly linear point configuration of a surface. Rather than allowing us to rely on a simple model of similitude in identifying the informational capacity of fabric, the topology immanent in fabric forces us to connect an 'inner' and imagined (imaged) rotation of a geometrically conceived surface with the relational nature of action that is drawn attention to in the external shape of a surface, an interlacing of image, surface and relational action that was conceived of long ago in Gottfried 
Wilhelm Leibniz's Faltentheorie (Bredekamp 2008). Fabric thus anticipates and recalls sequence as it unfolds in novel assemblages, always different and yet connected, perfectly exemplifying the Peirce's theory of the index, itself based on the reappraisal of the logic of relation based on topology (Burch 1991), in its gesturing capacity.

To understand how surface can do the work of both connectivity and closure, we need return to the work of Serres (1994), and to the nature of the patterned surface as topological and therefore geometric entity. Topology, the study of the spatial properties of things that remain invariant under deformation, is concerned with a complex of space, time, matter and process made manifest in the material imagination at work in weaving and shaping foldable, stretchable materials. Rather than directing attention to exact measurement for its own sake, topology captures spatial relations, such as continuity, neighbourhood, insideness and outsideness, disjunction and connection. Within a topological frame of reference, patterns are originating from the application of number systems such as those forming the quaternion group whose conceptual manipulation precedes the production of the pattern itself. We can compare the conceptual work supporting such patterns to that active in the manipulation of a Rubik's cube, conducive of a vision of the world in which the environment is no longer outside, but inside, invisible to the eye and yet conceptually accessible and predictable. Rotatable, to give off multiple and co-existing views, the surfaces of such artefacts are thus refractions of a single image in the round, inviting an idea of algebraic logic in which singularity and multiple iterations of one are the same (Mimika 1988; Glowczewski, 1989; Wagner, 1992; Povinelli, 2002; Myers 2004).

The geometric logic afforded by topology thus throws a light on how it is that a geometric surface can assign spatial value to temporal phenomena, a task of unique significance in island worlds, in which all intentional action is conducted at a distance and in relation to worlds whose workings needs to be made commensurate with what can be known by observation (Harrison, 2007). To fully grasp, however, how this patterned surface serves to index a closure and thus to demarcate and identify a singular person and associated object via its manifold topologically imagined nexus of relations, we need to return to the algebraic system at work in the example of the Cook Island piecework coverlet and to the mathematical ideas of Bernhard Riemann that imagines space as composed of a multiplicity of heterogeneous and yet inherently relational points. We will see that there is a rather surprising connection between the assembling of pieces of coloured cloth and the metric identification of a nexus of relations underpinning the complex genealogical system of the Cook Islands. As layers of patchwork cloak the body in the grave, gathering up the many persons identified as relations during life, a closure is achieved that is the ultimate expression of pervasive connectivity by turning the many back into one - an enigma that 
cannot be seen, but that issues forth an idea that binds people together more effectively and lastingly than words.

\section{Seascape Ontology and the Modelling of Complex Hierarchy}

The paradoxical idea behind Cook Island patchwork and its assemblage in the iterated patterns known to as tivaivai is that of a manifold of one. A manifold directs attention to itself in terms of its magnitude rather than the exact quantity represented. So it is that it is not important to Cook Islanders how many coverlets were cut and sewn by a woman during her lifetime and sent out as gifts to punctuate the life cycle of the relations she attached to herself, how many are returned to be lowered into her grave, or how many pieces cut from fabric in fact make up an individual coverlet. The manifold of coverlets in a grave or of the pattern comprising a single coverlet is judged only as relative in relation to others along a continuum (more or less). The idea of the manifold is in fact is commensurate with the idea of singularity. A brief excurse into ethnography will help to explain how this idea manifests itself around the making and deploying of coverlets and how it is a key to understanding the importance of the algebraic system that serves the instruction and recall of patterns and the understanding they help to deduce.

In the Cook Islands there are hardly any houses that do not have a grave on their front lawn, usually just outside the veranda or the entrance door, where women tend to sit and stitch their tivaivai. The grave structure is a large, underground and tiled tomb that resembles the house of the living, with foundation, platform and raised roof-structure. Although occasionally fenced in, the tomb is not a sacrosanct space, but a place that is fully integrated into domestic life - washing may be hung up to dry beneath the roof and flowerpots often decorate the platform beneath. Entering the house from the front, one inevitably walks past the grave. A sense of the central place occupied by the tomb emerges also from newspapers, where death days are memorialized by large columns of announcements, alongside those of birth and weddings. The departed, some of them having died sixty years ago, are recalled here with attention to detail: alongside a list of the names of families that have descended from the deceased, are pictures and recalled events that evince a personal touch. The dead, we realize, have not fully departed, but continue to share a transitory space with the living for a number of years. Only with the final anniversary, when the years after the burial equal the age of the person at death, is the person allowed to sink into the collective memory of ancestral connections, which connect the living with an apical ancestor. The many social relations who make up the biography of a person's life thus merge into the singularity of the apical ancestor in a process that is foreshadowed by the 
reconstitution of the social body of the deceased via the layering of the corpse with shrouds travelling in reverse, each coverlet signifying a relation made and sustained in life. In this way, the many relations that informed the life project of a person are in death becoming one again, synonymous with an apical ancestor.

We will see that this idea of the collapsing of the many into one is central to the experience of the stitching of the tivaivai, which, though a communal act, sees many women pulling the thread with the force of one (body). We will also see it in the idea of a pattern that can be stitched as one or replicated across the surface in as many often transitively arranged iterations as possible (restricted only by the size of the pieces of cloth that compose a pattern. Patterns are also internally manifold in that the assemblage of pieces can project varying 'views' (internal, external, sideways, top down) on what ostensibly, although misleadingly is seen to be depicted (usually flowers). Thus relations are created between any number of patchwork made by a woman during her life.

Tivaivai coverlets are the essential operatives of the idea of the polity or the social body equipped with offices and forms of power that outlast the mortal body of persons. And it is because there are many polities even on one and the same island in the Cooks that the idea of the one goes hand in hand with a seemingly competing notion of multiplicity where difference rather than sameness matters (Siikala 1996: 47-53; Küchler and Eimke 2009). Cook Island genealogy and its resulting system of hierarchy is of astonishing complexity when compared to that of other Maori speaking populations in Hawaii and Tahiti where the principle distinction is a matter of birth alone, distinguishing younger from elder brothers. In the Cook Islands a second factor is added to that of birth and this is the path taken by the apical ancestor and the location of the arrival of the canoe on the island. Being able to trace one's own path to the path of an ancestor legitimizes power over land, its access and its distribution. Relative position via autochthonous birth is marked by an applique coverlet (ta taura) that is gifted between households linked through marriage, and the power that such coverlets affirm is distinctive in terms of its reach and extension across generations conjoined by living memory. Knowledge of the path taken by the foreign element, however, is far more complex and difficult to ascertain, as it requires being able to translate the navigator's experience of the epic landing site into a formal system that entices recognition and consequentially validation as knowledge. It is as we will see the assemblage of pieces of precisely measured and cut cloth (taorel) into a pattern that can be repeated over and over again that achieves this effect of validation, gifted, poignantly, by a grandmother who is herself foreign born to her own adopted granddaughter, both repeating the journey taken by the apical ancestor.

It is important to describe the construction of the taorei in some detail, so as to convey how the pattern indexes both the epical path and the future relations it manifests. 
Composed of several thousand coloured squares or hexagons cut from shredded, readily coloured, roughly woven cotton imported from China, the core pattern of a taorei is a singular assemblage of a number of pieces of cloth of the same shape (usually a hexagon) and size, differing only in their colour. The core pattern is arranged in the shape of a square, and this squared core pattern is then replicated in an iterative and transitive manner across the surface of the quilt, which measures 3.5 to 5 meters in total. Considerable variation is possible in how the core pattern is arranged: it can be enlarged to fill the entire surface of the quilt, or it is replicated in either a horizontal or diagonally offset symmetry across the surface of the patchwork. A piece-work coverlet of this kind is carefully planned and worked out mathematically in order to avoid the situation that coloured cloth is left over or that not enough has been bought, as cloth available on the island is bought in bales whose colour changes subtly with each purchase, thus making the completion of a badly planned coverlet impossible. The planning starts with the metric of the core pattern.

The composition of the core pattern follows a number sequence recalled and instructed to others by the woman leading a sewing bee as numbers of coloured patches, each threaded up in turn by others to be taken home for sewing into place. Each core pattern is stitched by 2 woman, with the pattern itself being divided into triangular parts that mirror each other exactly. The number of times the core pattern is repeated across the surface of the quilt, each demanding 2 women for sewing, depends on the number of women working together in the sewing bee and will have been already reflected in the size of the individual pieces of cloth. The number sequence which appears as the outer framing row of coloured patches on each of the two sides of the triangle give the order of operation, allowing subsequent internal rows to be recalled and offered up as number of coloured patches to the group of workers.

Core patterns are thus metric in kind, remembered and instructed to others who are working together to stitch a coverlet. The number sequences running along the outer frame or path (pu) of the two sides of each triangle, doubled to create a square, are identical and are identifiable as non-commutative numbers sets, with the order in which the numbers are presented as coloured pieces being significant. The internal rows of each triangle are deduced from the sequence of the outer row, although some woman take liberty to create their own internal, doubled designs, deviating from the mathematics laid down in the path (pu) of the pattern. In mathematics we know such algebraic systems as forming quaternion groups, and Cook island women make use of this mathematical idea of a relation between two identical sets of sequence of numbers and rules for their combination. It is certainly not the case that Cook Island women are consciously constructing quaternion quilts, but they are using what Claude Levi-Strauss has aptly called the 'canonical formula' to imagine a complex 
system of numerical relations whose epistemic purchase we can begin to grasp when delving deeper into the question of how tivaivai works and what it does (Fischer, 2005).

We now understand that number sequences and their relation to one another evince the idea that any new sequence is never new but only a transformation of an existing relation, much in the same way as Claude Levi-Strauss (1963a) has shown for cycles of myth. Quaternion number systems are also used in digital rotation of geometric objects, making the reference of sequence to the wave formations associated with the landing site of an apical ancestor's canoe not as strange as it might first seem. In fact the sequence of numbers along the sides of a underpinning a patched pattern serve to translate a threedimensional geometric object, topologically conceived, into a two dimensional surface, thus allowing the relation between the pattern and the landing site of the apical ancestor to be more than merely metaphoric.

The giving and the receiving of tivaivai connects those who may be living apart for most of their lives, but they also demarcate moments of endings and beginnings of sequences of biographically charted events. In more than one way, each new tivaivai anticipates other ones to be made in the future, budding like the flowers on a tree. We may think of its surface as a skin-like, self-replicating and layered-cloth thing, whose successive folding and un-folding traces the frequent departures and the many returns that mark Cook Islands life. Marking points of departure and new beginnings, the stitched surface is a shroud that conjoins persons as its ties together those that are divided by fate and circumstance in life, at the same time as it differentiates those inhabiting the same small island. No doubt as a result of the complex system of hierarchy at work in the Cook Islands (Sijkala 1991), social differentiation is marked on the islands, with persons and households multiply intersecting with competing narrations of biographical relations as a result of intermarriage between distinct image based polities. The sewing bee operated by women heading up distinct households exists at the fault line of identity and differentiation, with each group sharing a bank account and acting as a unit in all aspects of economic and political life. The knowledge with which women engage sewing tivaivai as core economic and political activity enables them to assert an idea of relation, whose metric is shared and yet differentiated.

Anthropologists like to build models that have comparative significance and that also reflect the logic applied to understanding the behaviour of systems at the micro level of local life in ways Claude Levi-Strauss (1966) famously termed 'the science of the concrete.' The models proposed by anthropologists that enable one to understand the logical ordering that is permitting the distinct scales of sociality to be comprehended and to be predicted in their relation to one another have always been informed by mathematics, moving from a simple model of magnification to one of fractal organization whereby parts are encompassed by the whole, and the whole is generative of the parts which are infused by the whole (c.f. Kapferer 
2010: 191). While on the one hand the iterative construction of the tivaivai appears to resonate with this latter model, fractality as the value ascribed to social relation works only as long as we disregard the operative idea behind the tivaivai, which as assemblage invokes a translation of a three dimensional rotational object into a two dimensional surface using a metric that is specific to each assemblage while evoking the same elements and principles of combination. The concept fractality suggests a flat and homogenous space, yet is not helpful when trying to comprehend the differential curvature of wave formations associated with the different locations that are recalled by origin narratives and mapped by tivaivai.

Riemannian differential geometry invoked in this paper makes sense of such patchwork and the model of social relation it resonates in that each patchwork, while mapping a local Euclidian space, is continuous globally as it uses the same metric rules for its assemblage and yet locally discrete as it deploys distinct elements. By accentuating the conception and valuation of locality as differential principle while informing it with a shared metric, the piecework coverlet points up a model of society that is uniquely suited to capture the dynamic of maritime socialities whose global reach is complemented by internal differentiation and by an acute sense of the relational and social value of the local and the individual. Gilles Deleuze and Henri Bergson whose interests in cinematography was fuelled by their knowledge of Riemannian 'infinitesimal' or differential geometry would have likened tivaivai to the difference made by film to our own understanding of the seemingly incongruent relation between multiplicity and singularity, connectivity and closure (Duffy 2013:104). The formalized aesthetics of a surface that works in a Riemannian manner may well be far closer to our own experience than we may have expected.

\section{Conclusion:}

Cook Islanders' preoccupation with the making of large surfaces composed of patches carries on largely unnoticed. The disinterest it evokes, like so much of textile arts, in anyone who is not a 'maker' is provoked by our misconception that flat surfaces are also conceived as inert and shallow. Composite of iterative stuff like sand and threads, and inherently mobile and performative, the patterned surfaces described in this article coarticulate action and the representation of action in ways that demand we conceive of and imagine topological, transformative and systemic relations that invite multiple views on a continuous multiplicity of local space. The workings of the surfaces discussed in this paper resonate with ideas of multiplicity and closure and forms of sociability whose social effects are resonant with complex systems of hierarchy and an acceptance of instability and transformation. It is the recognition of assemblages on the surface of coverlets as the qualitative identification of local space via quantitative means that binds people to each other passionately, and with an endurance and reach that surpasses the limitations of memory. 
Untrained in the art of abstract metric modelling, lacking the vocabulary to attend to a logic of relation that dwells in the concrete, and ill equipped to think with geometry in mind or to relate what is visible with what is invisible, it is unsurprising that social science has such a hard task in theoretically appraising what patterned surfaces are, how they work and what they do. That the surfaces discussed in this article are at home in maritime societies in which information exchange operates across vast distances should make us look at our own preconceptions around metric coding and the possibility of formalized informational surfaces that connect while achieve closure, and rethink of how surfaces can bind an inner, profoundly imagistic and yet metric and geometric world with an intentional relation to the world. It is by recognising the relation between mathematics, ideas and the 'physical real' captured by Albert Lautman (2011) and recalling the work on differential geometry by Bernhard Riemann that we can understand the kind of worlding in which informational surfaces can thrive.

\footnotetext{
${ }^{1}$ As described by Tim Ingold (2007) in his treatise of our penchant for navigating by walking along paths that have a beginning and end with lots of memorable view in between.
}

2 One is reminded of Walter Benjamin's (1966) work on Material Translation and the Language of Things with relations internally held that inform understanding and translation alike; as well of the work by Patrice Maniglier (2006; 2013) on the enigma of the sign whose relations are immanent ("it represents itself within itself" Maniglier 2013: 108).

${ }^{3}$ In contrast to Euclidean 'finite' geometry of three-dimensional linear point configurations, differential geometry considers curved three dimensional spaces, first theorized by Bernhard Riemann in 1863 who extended Euclidean geometry to non flat spaces. Rather than operating according to a geometry of local spaces, as Euclidean geometry does, Riemannian infinitesimal or differential geometry operates according to a conception of space that is global, but constituted by an assemblage of locally discrete and therefore heterogeneous spaces (see Duffy 2013: 104).

4 The realization that ideas of relation are captured by mathematics has inevitable implications for social science that has far too long remained ignorant of the fact that the idea of relation is fundamentally a mathematical one (Gell 1998; Ascher 2002; Krämer and Bredekamp 2013).

${ }^{5}$ This idea, first articulated in Simmel's 2016 essay on Rembrandt, and his later writings on artificial sociability and the sociology of aesthetics are captured in De La Fuente's (2008) essay on the sociology-aesthetic nexus in Georg Simmel's thought.

6 "'Much of what we believe we 'see' directly is in fact not seen at all, but rather, as one says, is 'deduced'.'(Simmel 2005: 17).

7 Ingold 2008.

${ }^{8}$ Dimensional translation has been famously analysed by Claude Levi Strauss (1963b) in his work on split representation involving the characteristic splitting of an image so that two halves face one another, can be traced across both Asian and American art. By tracing the splitting of an image to the actions informing the process of the creation of this pattern via the translation of an image from three dimensional into two dimensional form, Lévi-Strauss was able to draw a parallel with the characteristic collapsing of the concept of person with a socially effective office in ways symptomatic of hierarchical societies in which men compete over structurally and genealogically conferred status that outlasts the individual person. 


\section{References}

Arkana, Elizabeth (1986) Hawaiian Quilting: A Fine Art. Honolulu: Hawaiian Childrens Society. Ascher. Marcia (2002) Mathematics Elsewhere. Princeton: Princeton University Press.

Babadzan, Alain (1993) Les Depouilles des Dieux: Essai sur la Réligion Tahitienne a l'Epoque de la Découverte. Paris: Editions de la Maison des Sciences.

(2003) The gods stripped bare. In: Colchester, Chloe (ed) Clothing the Pacific. Oxford: Berg: $25-51$

Benjamin, Walter (1996) On Language as Such and On the Language of Man. In: Bullock, Marcus and Jennings, Michael (eds) Walter Benjamin Selected Writings Volume I: 1913-1926, eds.. Cambridge, MA, Harvard University Press: 62-74.

Boas, Franz (1911) Introduction. In: Boas, Franz (ed) Handbook of the American Indian Languages. Bureau of American Ethnologie Bulletin 40. Washington: Smithonian Institution. Reprinted 1966 University of Nebraska Press.

Boas, Franz (1927) Primitive Art. Harvard: Peabody Museum Press.

Bredekamp, Horst (2008) Die Fenster der Monade: Gottfried Wilhelm Leibniz' Theater der Natur und Kunst. Berlin: Akademie Verlag.

Brunt, Peter, Nicholas Thomas, Sean Mellon, Lissant Bolton, Damien Skinner, Deidre Wilson and Susanne Küchler (2011) Art in Oceania: A New History. London:

Thames\&Hudson.

Burch, Robert (1991) A Peircean Reduction Thesis: The Foundations of Topological Logic. Lubbock, Texas :Texas Tech University Press.

Clark, Andy (2001) Mindware: An Introduction to the Philosophy of Cognitive Science. Oxford: Oxford University Press.

Connor, Simon (2004) Topologies: Michel Serres and the Shapes of Thought. Anglistik 15: 105-17.

Damon, Frederick (2016) Trees, Knots and the Outrigger: Environmental Knowledge in the Northeast Kula Ring. Oxford: Berghahn.

Deacon, Abel B. (1934) Malekula: A Vanishing People in the New Hebrides. Wedgewood, C.H. (ed) London: Routledge.

De La Fuente, Eduardo (2008) The Art of Social Forms and the Social Forms of Art: The Sociology-Aesthetics Nexus in Georg Simmel's Thought. Sociological Theory 26 (4): 344-363.

Deleuze, Gilles (1993) The Fold: Leibniz and the Baroque. Translated T. Conley. Minneapolis: Minnesota University Press. Original edition, Le pli. Leibniz et le baroque. Paris: Minuit. 1988

Deleuze, Gilles and Felix Guattari (1987) A Thousand Plateaus: Capitalism and Schizophrenia. Translated by B. Massumi. Minneapolis: Minnesota University Press. Original edition, Mille plateaux, Capitalisme et schizophrenie. Paris: Minuit. 1990.

Duffy, Simon (2013) Bergson and Riemann on Qualitative Multiplicity. In his Deleuze and the History of Mathematics. London: Bloomsbury Academic: 89-117.

Dumont, Louis (1980) Homo Hierarchicus. $2^{\text {nd }}$ edition. Chicago: University of Chicago Press.

Fischer, Gwen L. (2005). The Quaternion Quilts. Focus 25(1): 4-5.

Forge, Anthony (1973) Style and Meaning in Sepik Art. In his Primitive Art and Society. Oxford: Oxford University Press: 169-192.

Gallese, Vittorio (2000) The Inner Sense of Action: Agency and Motor Representation. Journal of Consciousness Studies 7 (10): 23-40.

Gell, Alfred (1985) How to Read a Map: Remarks on the Practical Logic of Navigation'. Man (NS) 20(2): 271-86.

(1995) Closure and Multiplication: An Essay on Polynesian Cosmology and Ritual. in Itenau, Andre and Daniel de Coppet (eds) Cosmos and Society in Oceania. Oxford: Berg.

(1998) Art and Agency. Oxford: Oxford University Press.

Gladwin, Thomas (1970) The Past is a Big Bird. Cambridge, MA: Harvard University Press. 
Gloczweski, Barbara (1989) A Topological Approach to Australian Cosmology and Social Organisation. Mankind 19(3): 227-40.

Hammond, Joyce (1986) Polynesian Women and Tifaifai Fabrications of Identity. The Journal of American Folklore 99(393): 259-79.

Harrison, Simon (1992) Ritual as Intellectual Property. Man (NS) 27(2): 225-44. (1999) Identity as a Scarce Resource. Social Anthropology 7(3): 239-51. (2007) Fracturing Resemblances: Identity and Mimetic Conflict in Melanesia and the West. Oxford: Berghahn Books.

Henari, Amiria, Martin Holbraad and Sari Wastell (eds) (2007) Introduction: Thinking through Things. In their eds. Thinking Through Things: Theorising Artefacts Ethnographically. London: Routledge: 1-31).

Hutchins, Edwin (1995) Cognition in the Wild. Cambridge MA: MIT Press.

Ingold, Tim (2007). Lines: A Short History. London: Routledge.

---- (2008). Bindings against Boundaries: Entanglements of Life in an Open World. Environment and Planning A 40(8): 1796-1810.

Jones, Stella (1973) Hawaiian Quilts. Honolulu: Hawaii University Press.

Kapferer, Bruce (2010). Louis Dumount and a Holist Anthropology. In: Otto, Ton and Nils Brubant (eds) Experiments in Holism. London: Blackwell Publishing: 187-208.

Knappett, Carl (2005) Thinking Through Material Culture: An Interdisciplinary Perspective. Pennsylvania University Press.

Küchler, Susanne and Graeme Were (2005) Pacific Pattern. London: Thames\&Hudson.

----- and A. Eimke (2009) Tivaivai: The Social Fabric of the Cook Islands (photo A. Eimke). London: British Museum Press.

Krämer, Sybille and Horst Bredekamp (2013) Culture, Technology, Cultural Techniques - Moving Beyond Text. Theory, Culture and Society 30(6): 20-29.

Latour, Bruno (1990) Drawing Things Together. In Lynch, Michael and Simon Woolgar (eds) Representation in Scientific Practice. Cambridge, MA: MIT Press: 19-69

Lautmann, Albert (2011) Mathematics, Ideas and the Physical Real. Trans. S. Duffy of Lautmann 2006. London: Continuum.

Leach, Edmund (1954) Political Systems of Highland Burma: A Study of Kachin Social Structure. London: London School of Economics and Political Sciences.

Levi-Strauss, Claude (1969) The Elementary Structures of Kinship (trans. J.H. Belle, J.R. von Sturmer and R. Needham). Boston: Beacon Press.

--(1966) The Science of the Concrete. In his The Savage Mind. Chicago: University of Chicago Press: 1-22.

(1963a). The Structural Study of Myth. In his Structural Anthropology; translated by C.Jacobson, vol 1, New York: Basic Books: 202-208.

(1963b) Split representation in the art of Asia and America. In his Structural Anthropology. New York: Basic Books: 245-269.

Malafouris, Lambros (2013) How Things Shape the Mind. Cambridge, MA: MIT Press.

Maniglier, Patrice (2013) The Order of Things. In Falzon, Christopher,Timothy O'Leary, and Jana Sawicki (eds) A Companion to Foucault. London, New York: Blackwell Publishing: 103-121.

(2006) La vie enigmatique des signes: Saussure et du structuralisme. la naissance. Paris: Editions Leo Scheer

Mimika, Jadran (1988) Intimations of Infinity: The Cultural Meanings of the lqwaye Counting and Number Systems. London: Bloomsbury Press.

Morava, Jack (2003) On the Canonical Formula of C. Levi-Strauss. Mathematics Subject Classification. 03G30,91Dxx,92Hxx. 11 June.

--------(2005) From Levi Strauss to Chaos and Complexity. In Mosko, Mark and Frederick Damon (eds) On the order of Chaos: Social Anthropology and the Science of Chaos. Oxford: Berghan: 47-64.

Mosko, Mark and Frederick Damon (2005) On the Order of Chaos: Social Anthropology and the Science of Chaos. Oxford: Berghahn. 
Mosko, Mark (2005) Introduction: A (Re)Turn to Chaos. In Mosko, Mark and Frederick. Damon (eds) On the Order of Chaos: Social Anthropology and the Science of Chaos. Oxford: Berghahn: 1-47.

Myers, Fred (2004) Ontologies of the Image and Economies of Exchange. American Ethnologist 31(1):1-16.

Pogglioli, Vicky (1988) Patterns from Paradise: The Art of Tahitian Quilting. Pittstown, NJ: Main Street Press.

Povinelli, Elizabeth (2002) The Cunning of Recognition: Indigenous Alterities and the Making of Australian Multiculturalism. Durham, NC: Duke University Press.

Rio, Knut (2007) The Power of Perspective: Social Ontology and Agency on Ambrym Island, Vanuatu. Oxford: Berghahn Books.

Rongokea, Lynnsay (1992 [2001]) The Art of Tivaevae: Traditional Cook Islands Quilting. Honolulu: University of Hawaii Press.

Serres, Michel (1994) Atlas. Paris: Editions Julliard.

Severi, Carlo (2014) Transmutating Beings: A Proposal for an Anthropology of Thought. HAU: Journal of Ethnographic Theory 4(2): 41-71.

Siikala, Jukka (1996) The Elder and the Younger - Foreign and Autochthonous Origin and Hierarchy in the Cook Islands." In: Fox, James and Clifford Sather eds Origins, Ancestry and Alliance: Explorations in Austronesian Ethnography. Canberra: ANU Press: 43-54.

- (1991) Akatokamava: Myth, History and Society in the Southern Cook Islands. Auckland: The Polynesian Society in Association with the Finnish Anthropological Society, Helsinki.

Simmel, Georg (1950) Sociability: An example of pure, or formal sociology. In The Sociology of Georg Simmel, translated and edited by Kurt H. Wolff. New York: Free Press: 40-57. -(2005) Rembrandt: An essay in the Philosophy of Art. Translated and edited by Scott, Alan and Helmut Staubmann. New York: Routledge. Original Publication Leibzig: Kurt Wolf. 1916.

Starr,Gabrielle (2013) Feeling Beauty: The Neuroscience of Aesthetic Experience. Cambridge, Mass.: MIT Press.

Wagner, Roy (1992). The Fractal Person. In: Godelier, Maurice and Marilyn Strathern (eds) Big Men and Great Men: Personifications of Power in Melanesia. Cambridge: Cambridge University Press: 159-174.

Washburn, Dorothy and Crowe, David (1988) Symmetry of Culture: Theory and Practice of Plane Pattern Analysis. Seattle: University of Washington Press. -(2004) Symmetry Comes of Age: The Role of Pattern in Culture. Seattle: University of Washington Press.

Wiberg, M. and E, Robles (2010) Computational Composition: Aesthetics, Materials and Interaction Design. International Journal of Design 4(2): 65-76.

Bio:

Susanne Küchler is Professor of Anthropology and Material Culture at University College London. She has conducted long term ethnographic fieldwork in both island Melanesia and Eastern Polynesia on the artefacts of knowledge economies. Her work on the history of the take up or rejection and the contemporary transformations of cloth and clothing in Oceania has led to comparative work on materials and society. Her research more recently has focused on the cognitive work of images against the background of a comparative inquiry into the relation between mathematics and the modelling of complex systems in the artefacts operative in Oceanic knowledge economies. Her contribution to the theoretical appraisal of social memory in anthropology and art history is grounded in ethnography, comparing the difference made by the articulation of image based polities in island Melanesia and Eastern Polynesia to culture and society, focusing in particular on how diverse 
prototypical and classificatory regimes of intellectual property shape distinct societal approaches to identity and integration. 